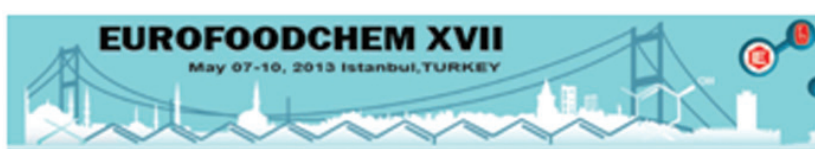

EuroFoodChem XVII

7-10 maio 2013 em Istambul, Turquia

Após o sucesso de edições anteriores, o XXVII EuroFoodChem decorrerá na capital da Turquia, local de encontro do Oriente e Ocidente, cidade que reflete o cruzamento de diferentes continentes e culturas. A série de conferências EuroFoodChem é organizada sob os auspícios da Divisão de Química Alimentar da EuCheMS (Associação Europeia de Química e Ciências Moleculares). O EuroFoodChem XVII incidirá sobre os seguintes tópicos principais, entre outros: Novos desenvolvimentos no processamento de alimentos; Novos alimentos; Alimentos e ambiente; Micro e macronutrientes: biodisponibilidade e estratégias de avaliação; Análise risco/benefício e avaliação de risco; Efeitos do processamento nos constituintes dos alimentos; Contaminantes; Alergénios; Adulteração e autenticidade de alimentos; Ingredientes e alimentos funcionais; Métodos analíticos rápidos; Nanomateriais em alimentos; Alimentos tradicionais: propriedades físico-químicas, etc.

A data limite para submissão de resumos para trabalhos cujos autores pretendam apresentar no formato de comunicação oral é dia 4 de janeiro de 2013, ao passo que trabalhos cuja apresentação seja feita em formato de poster poderão ser submetidos até 31 de janeiro de 2013.

Para a obtenção de mais informações sobre o evento, consultar a respetiva página web.

E: arber@arber.com.tr

URL: https://www.arber.com.tr/eurofoodchemxvii.org/ index.php/home

7th International Congress on Pigments in Food (pif 2013) 18-21 junho 2013 em Novara, Itália

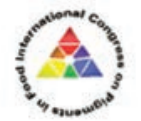

7 th International Congress on

Pigments

in food

18 th -21 th

June 2013

Novara, Italy

norte de Itália (Piemonte). Este congresso que terá lugar entre os dias 18 e 21 de junho de 2013, é organizado sob os auspícios da EuCheMS, e este ano estará subordinado ao tema "...tecnologia alimentar para a saúde, passando pelas cores...".

O principal objetivo do congresso consiste em fornecer uma possibilidade de encontro e de discussão para os cientistas que lidam e estudam diferentes aspetos relacionados com os pigmentos de alimentos, tais como químicos e químicos alimentares, agricultores, nutricionistas, mas também pessoas da indústria de todo o mundo.

Os tópicos principais que se pretendem ver abordados neste congresso são os seguintes: (i) Química e bioquímica de pigmentos, (ii) Extração e isolamento, (iii) Novas (bio) tecnologias verdes/brancas para a extração de pigmentos, (iv) Estabilização e formulação, (v) Análise e medida da cor, (vi) Toxicologia, (vii) Propriedades bioativas de pigmentos, (viii) Pigmentos como ingredientes funcionais e (ix) Novas fontes de pigmentos (incluindo resíduos agroalimentares).
A página do encontro encontra-se em construção, mas pode desde já ter acesso às informações importantes, sugerindo-se a consulta frequente da mesma, onde brevemente serão colocadas mais informações.

E: pif2013@pif2013.org

URL: http://pif2013.org

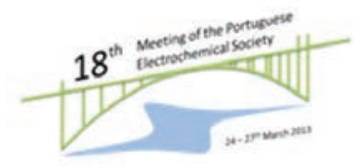

\section{Meeting of the Portuguese Electrochemical Society}

\section{4-27 março 2013 no Porto}

O $18 .^{\circ}$ Encontro da Sociedade Portuguesa de Eletroquímica irá decorrer no Porto, entre os dias 24 e 27 de março. 0 encontro destina-se a todos os investigadores que trabaIham e se dedicam ao estudo da fascinante área que é a eletroquímica. Uma das palestras já confirmadas será proferida pelo Professor Richard G. Compton (Universidade de Oxford, Reino Unido) o qual é autor/coautor de mais de 1100 artigos científicos na área da eletroquímica/ciências eletroquímicas. De salientar igualmente que será publicado um número especial da revista da Sociedade Portuguesa de Eletroquímica, Portugaliae Electrochimica Acta, com base nas contribuições apresentadas nesta conferência.

Mais detalhes podem ser obtidos na página web do evento.

E: 18spe@fc.up.pt

URL: http://www.fc.up.pt/18spe

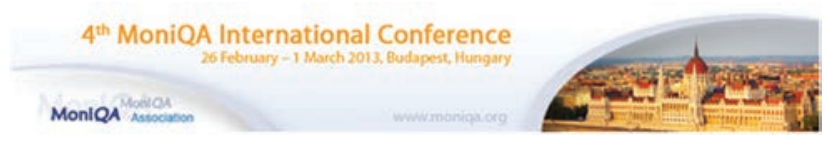

4th Moniqa International Conference

26 fevereiro - 1 março 2013 em Budapeste, Hungria

A $4 .^{\text {a }}$ Conferência Internacional MoniQA irá decorrer em Budapeste, no Hotel Novotel Budapeste Congress, entre os dias 26 de fevereiro e 1 de março de 2013. A conferência é organizada pela Associação MoniQA, com sede em Viena, Áustria, em cooperação com a Universidade de Tecnologia e Economia de Budapeste (BME), Hungria. O tema desta 4. ${ }^{\text {a }}$ conferência MoniQA, será "Segurança Alimentar sob a Pressão Global causada por Mudanças Climáticas, Segurança Alimentar e Crises Económicas". Este tema pretende incentivar a discussão de várias questões alimentares emergentes e persistentes relacionadas com a segurança alimentar, e os desafios analíticos e legais relevantes que surgem com a perspetiva da globalização, alterações climáticas e possíveis crises económicas. Esta conferência tradicionalmente atrai participantes de vários países, esperando-se a presença de cerca de 200 participantes de cerca de 35 países diferentes, provenientes do meio académico, mas também da indústria e de diferentes organizações, incluindo representantes de consumidores e de meios de comunicação, organizações governamentais, legisladores, prestadores de serviços, etc. A apresentação de novas abordagens e desenvolvimentos será realizada através de apresentações orais e em formato de poster. Em ambos os casos será incentivada a discussão de ideias e troca de conhecimentos.

Para mais informações, sugerimos a consulta da página eletrónica da conferência.

E: bugyi@mail.bme.hu

URL: http://budapest2013.moniqa.org 


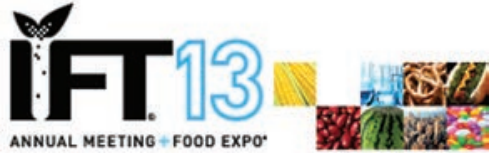

13th Institute of Food Technologists Annual Meeting \& Food Expo

13-16 julho 2013 em Chicago, E.U.A.

A 13. ${ }^{a}$ edição do encontro anual do Institute of Food Technologists (IFT), considerado uma das maiores exposições e fórum de discussão na área da ciência alimentar a nível mundial, decorrerá, em julho de 2013, na cidade de Chicago, nos Estados Unidos da América. Este evento global atrai participantes de todo o mundo, juntando os mais reputados profissionais da indústria agroalimentar, investigadores e académicos, membros de organizações governamentais, entre outros participantes, todos eles com interesses nas mais diversas facetas da ciência e tecnologia alimentar. Regra geral, os participantes neste encontro pretendem adquirir novos conhecimentos e estar a par das forças motrizes por trás das inovações e tendências que afetam os consumidores. Os principais objetivos desta série de encontros consistem em (i) proporcionar aos participantes novas descobertas e aplicações recentes no campo da ciência alimentar, (ii) permitir conhecer, tocar, provar novos produtos e conhecer as tecnologias que estiveram na sua génese, (iii) estabelecer novos contactos e relações empresariais, (iv) expandir o conhecimento de base e (v) fazer novos contactos que permitam a evolução da carreira de diferentes profissionais.

Durante os quatro dias do encontro, peritos de diferentes setores (industrial, I\&D e órgãos governamentais), partilham os seus conhecimentos únicos durante mais de 100 sessões e de 1000 apresentações, abordando temas que vão desde novos benefícios para a saúde, segurança alimentar e inovações de produtos, até às mais recentes tendências de consumo, bem como receios dos consumidores. Os tópicos abordados incluirão os seguintes: Segurança alimentar, Benefícios para a saúde e nutrição, Processamento alimentar e embalagem, Desenvolvimento de produtos \& inovação de ingredientes, Sustentabilidade, Políticas públicas, leis alimentares e regulamentos, Microbiologia alimentar, Química alimentar, Engenharia alimentar, Análise sensorial, entre outros. De salientar ainda que, nos dias que precedem o encontro, o IFT disponibiliza 8 a 10 cursos de curta duração diferentes. Mais informações podem ser obtidas na página Web do evento.

E: info@ift.org

URL: http://www.am-fe.ift.org/cms

2013 International Association for Food Protection (IAFP) European Symposium on Food Safety

15-17 maio 2013 em Marselha, França

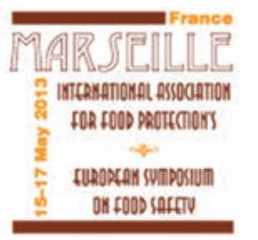

O Simpósio Europeu IAFP sobre Segurança Alimentar, organizado pela Associação Internacional para a Proteção Alimentar (IAFP), irá decorrer em Marselha, França, no Parque Chanot Convention Centre, nos dias 15 a 17 de maio de 2013. Estes simpósios têm sido organizados anualmente desde 2005, com o objetivo de contribuir para a melhoria futura no campo da segurança alimentar, proporcionando um fórum para a troca de ideias entre os participantes provenientes da industria, governo e academia de países Europeus. Mais informações sobre o programa científico e as diferentes sessões temáticas que serão abordadas no encontro, serão disponibilizadas brevemente na página Web do encontro.

E: info@foodprotection.org

URL: http://www.foodprotection.org/europeansymposium

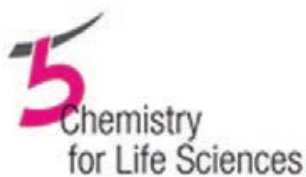

5th European Conference Chemistry for Life Sciences 10-12 junho 2013 em Barcelona, Espanha

A 5. ${ }^{a}$ Conferência Europeia de Química para as Ciências da Vida realizar-se-á em Barcelona, entre os dias 10 e 12 de junho. Esta conferência é uma atividade da Divisão de Química para as Ciências da Vida da EuCheMS, sendo organizada conjuntamente por esta associação, pelo Institute for Research in Biomedicine (Barcelona), Real Sociedad Española de Química e Societat Catalana de Química. A conferência apresentará como tópicos a serem discutidos os seguintes, entre outros possíveis: Bioconjugados - novas metodologias e aplicações em biomedicina, Bionanomateriais - nanopartículas usadas em terapia e diagnóstico, Quimiogenómica, Análise conformacional de biomacromoléculas, Desenho e síntese de derivados terapêuticos de ácidos nucleicos, Desenvolvimento de fármacos para alvos desafiantes, Reações enzimáticas: novos mecanismos, Química de glúcidos, Modulação de interações proteína-proteína, Reconhecimento molecular e biocatálise, Neuroquímica: mecanismos moleculares de neurodegeneração, Novas tendências em Química Bioinorgânica, Novas tendências em Química Medicinal, Química de proteínas e péptidos, e Síntese de compostos biologicamente ativos. De referir ainda a possibilidade de atribuição de 15 bolsas para custeio de viagem a jovens investigadores (nascidos após 1 de janeiro de 1981).

Para saber como se candidatar a estas bolsas (candidaturas até 15 de março de 2013) deverá consultar a página do evento.

E: eccls2013@vibocongresos.com

URL: http://www.5ecclsbarcelona.com

Second International Congress on Cocoa, Coffee and Tea 9-11 outubro 2013 em Nápoles, Itália

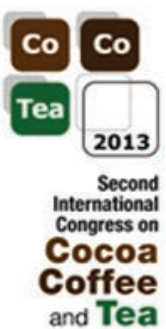

Dado o sucesso da $1 .^{a}$ edição CoCoTea, realizar-se-á entre 9 e 11 de outubro de 2013, com o patrocínio da Food Chemistry Division da EuCheMS e da Sociedade Internacional de Reações de Maillard (IMARS), o $2 .^{\circ}$ Congresso Internacional CoCoTea, um encontro dedicado sobretudo à ciência do cacau, chocolate, café, chá e produtos relacionados. Os tópicos principais, envolvendo estas matrizes, incidirão na Química Alimentar (composição, qualidade e segurança, aspetos analíticos, processamento, etc.), Tecnologia Alimentar (novas tecnologias, micro e nano-encapsulação, embalagem, impacto de processamento na segurança e qualidade) e Nutrição e Saúde (compostos bioativos e biodisponibilidade, estudos in vitro e in vivo, efeitos fisiológicos, etc.).

E: info@cocotea2013.org

URL: http://www.cocotea2013.org

Secção compilada por Joana Amaral (bquimica@ipb.pt)www.spq.pt 
